\title{
Forecasting Exchange Rate Across Countries with Gold Price as Exogenous Variable using Transfer Function and VARIX Model
}

\author{
${ }^{1}$ Alhassan Sesay*, ${ }^{2}$ Suhartono and ${ }^{3}$ Dedy Dwi Prastyo \\ ${ }^{1,2,3}$ Department of Statistics, Faculty of Science and Data Analysis \\ Institut Teknologi Sepuluh Nopember, 60111 Surabaya, Indonesia \\ ${ }^{1}$ United Methodist University, Freetown, Sierra Leone \\ ${ }^{1}$ United Muslim Association Secondary School, Freetown, Sierra Leone \\ ${ }^{*}$ Corresponding author: dedy-dp@statistika.its.ac.id
}

Article history

Received: 13 May 2019

Received in revised form: 26 July 2020

Accepted: 26 July 2020

Published online: 1 December 2020

\begin{abstract}
Investors and collectors hold gold as protection for their savings and wealth at large. Gold does not pay interest like treasure bonds or savings accounts, but current gold prices often reflect increases and decreases of an asset. This research aims to provide a model for the relationship between the exchange rate, which is vital in exporting gold, and gold prices across countries. The Australia, Brazil, and South Africa exchange rates are used as a case study against the gold price. The ARIMA model is used for forecasting gold price as an input for the Transfer Function and VARIX models. The Transfer Function model only considers the relationship between gold prices as input with the exchange rate in each country, whereas the VARIX model also considers the interrelationship between exchange rates in these countries. Daily data is used for the period 1st June 2010 to the 28th February 2018. The RMSE and MAPE are used as criteria for selecting the best model. The results show that VARIX is the best model for forecasting the Australian exchange rate, while the Transfer function is the best model for forecasting South African and Brazilian exchange rates.
\end{abstract}

Keywords Exchange Rate; Gold Price; Transfer Function; VARIX; RMSE; MAPE.

Mathematics Subject Classification 62M10, 62P20, 91B84

\section{Introduction}

Gold is one of the most valuable metals globally as rising cost indicates an expectation of a strong economy, and these strong economies give rise to inflation. There is only a limited amount of gold, so any increase, decrease, or a sudden change to the supply or demand of gold will impact prices and affect the exchange rates. Investors and collectors hold gold as protection for their savings and their wealth at large. Gold is also seen as a hedge against inflation and currency devaluation as it is traded in US dollars. Interest rates affect the price of 
gold when interest rates moved higher when the price of gold tends to fall since it costs more as it shows that fluctuations influence exchange rates. Currency values fluctuate, but gold values in terms of ounces can stay more stable in the long term. The demand for gold has expanded with its extensive use in industrial goods and the jewelry sector in recent years [1]. Humans could use gold as a form of wealth and also as a form of currency. Since gold prices fluctuate when people lack confidence in governments or financial markets, world events often impact gold price because it is viewed as a safe source when there is a problem. Forecasting can be used in many ways, but one of its most objectives is to predict its future values.

According to the economist's point of view, the United States (U.S) dollar was chosen for the Bretton Woods system because the U.S. was easily the world strongest economy coming out of the Second World War. Unlike the other strong nations, the U.S does not have to repair infrastructure due to the price of gold was pegged to the U.S dollar.

Several researchers have proposed different mathematical models to forecast gold prices and exchange rates. Some of these models are the Generalized Autoregressive Conditional Heteroscedasticity (GARCH) model, Threshold Autoregressive (TAR) model, Self-Exciting Threshold Autoregressive (SETAR) model, and Artificial Neural network (ANN) [2]. Similarly, the determinants of the gold price from some different macroeconomic factors in Sri Lanka were investigated using ARIMA and VAR models. They found out that the previous months' gold price rate highly affects the current months gold price rate [3]. Monthly gold price data and cointegration regression techniques were used to analyze the U.S' general inflation and the world at large, the U.S dollar exchange rate, and another shock. They suggested that sizeable shortrun movements in the gold price are related to the gold price rising by utilizing inflation's total rate. They also confirmed that movements in gold's nominal price are controlled by short-run influences [4].

An inter-dealer order flow explains that a significant daily exchange rate changes and argued that flows are the main cause of exchange rate movements [5]. Similarly, weekly flows also help explain exchange rate movements based on recent findings. Furthermore, other researchers have found out that gold prices are affected by the U.S economy rather than the worldwide economic conditions. The U.S dollar is providing the exchange rate required for international liquidity. Hence a negative relationship is established between the exchange rate and gold price [6-7].

Currently, South Africa and Brazil also enjoy strong bilateral relations as symbolized by high-level visits and various agreements signed across a number of sections since 1994. The relationship between the two countries is also underpinned by a common desire to influence the global agenda in the 21st century in a manner that reflects the aspirations of developing countries. The key sectoral areas of cooperation include trade and industry, health, arts and culture, tourism, and environmental affairs. Brazil remains South Africas largest trading partner in Latin America, while Australia has a lot of additional advantages with South Africa in terms of international trade, the business culture, accounting practices, and English, which is the official language in both countries by Jordan [8].

Given this, it will be interesting to evaluate these countries' exchange rates with respect to gold price as they have seen themselves as partners in trade, development, and factor endowments. This research focuses on forecasting exchange rates across countries with gold prices as an exogenous variable using the Transfer function and VARIX compared to the ARIMA model. The result of this model is obtained by looking at the smallest RMSE and MAPE values. The first part of the study looked at a detailed literature review on exchange rate followed by 
the models, the data sets are elucidated. Subsequently, data is analyzed, then the conclusion and recommendations are made.

\section{$2 \quad$ Literature Review}

\subsection{ARIMA Model}

The ARIMA model, as formulated in (1), is a common model for forecasting. In addition to being used for non-seasonal models, ARIMA models can also be used for the seasonal model. The seasonal time series model is a time series that has certain properties, e.g. yearly for monthly time series, or weekly. Seasonal ARIMA models are expressed as (see e.g. [9-11]):

$$
\Phi_{p}\left(B^{s}\right) \Phi_{p}(B)(1-B)^{d}\left(1-B^{s}\right)^{D} Y_{t}=\theta_{q}(B) \Theta_{Q}\left(B^{s}\right) a_{t}
$$

where

$\Phi_{p}(B)=$ coefficients of non-seasonal AR components $p$ degree, with the following description $\Phi_{p}(B)=\left(1-\Phi_{1} B-\Phi_{2} B^{2}-\ldots-\Phi_{p} B^{p}\right)$,

$\Phi_{p}\left(B^{s}\right)=$ coefficients of the seasonal AR component $s$ with translation as follow

$\Phi_{p}=\left(1-\Phi_{1} B^{s}-\Phi_{2} B^{2 s}-\ldots-\Phi_{p} B^{p s}\right)$,

$\theta_{p}(B)=$ MA component coefficients are non-seasonal with $q$ degree with the translation as follows

$\theta_{q}(B)=\left(1-\theta_{1} B-\theta_{2} B^{2}-\ldots-\theta_{q} B^{q}\right)$,

$\Theta_{Q}\left(B^{s}\right)=$ seasonal MA component coefficient $s$ with translation

$\Theta_{Q}\left(B^{s}\right)=\left(1-\theta_{1} B^{s}-\theta_{2} B^{2 s}-\ldots-\theta_{Q} B^{Q s}\right)$

$(1-B)^{d}=$ operator for differencing order $d$

$\left(1-B^{s}\right)^{D}=$ operator for seasonal differencing $s$ order $D$

$a_{t}=$ the residual value at the time $t$ that satisfy the white noise assumption.

\subsection{Transfer Function}

The Transfer function model is based on the relationship between time series response data (output series) with one or more predictors or input series [12]. In other words, the transfer function is a model that describes the predicted value of time ahead of a time series variable based on past values. The general form of a transfer function for a single input $\left(x_{t}\right)$ and the single output $\left(y_{t}\right)$ is expressed in (2) and (3) as follows:

$$
y_{t}=v_{0} x_{t}+v_{1} x_{t-1}+v_{2} x_{t-2}+\ldots+\eta_{t}=v(B)+\eta_{t}
$$

where $y_{t}$ is a stationary output array, $x_{t}$ is a series whose input is stationary, and is an error component to follow an ARMA model, with

$$
v(B)=\frac{\omega_{s}(B) B^{b}}{\delta_{r}(B)} \quad \text { and } \quad \eta_{t}=\frac{\theta_{q}(B)}{\phi_{p}(B)} a_{t}
$$


where

$$
\begin{aligned}
\omega_{s}(B) & =\omega_{0}-\omega_{1} B-\ldots-\omega_{s} B^{s}, \text { i.e. moving average operator of order } s, \\
\delta_{r}(B) & =1-\delta_{1} B-\ldots-\delta_{r} B^{r}, \text { i.e. the autoregressive operator of order } r, \\
a_{t} & =\text { residual value at time } t .
\end{aligned}
$$

\subsection{Vector Autoregressive Exogenous Variable (VARX)}

Vector Autoregressive with Exogenous Variables (VARX) is an expansion of the VAR model by adding exogenous $X$ variables at the right (see equation (4)). If the data is not stationary in mean, then it should be differenced such that the model becomes Vector Autoregressive Integrated with Exogenous Input [13]. The VARIX $\left(p, d . s^{*}\right)$ model can be written as:

$$
\Phi_{p}(B)(1-B)^{d} Z_{t}=\theta_{s^{*}}^{*}(B) X_{t}+a_{t}
$$

where

$$
\Phi_{p}(B)=\left(I-\Phi_{1} B-\Phi_{2} B^{2}-\cdots-\Phi_{p} B^{p}\right), \quad \theta_{s^{*}}^{*}(B)=\theta_{0}^{*}-\theta_{1}^{*} B-\cdots-\theta_{s^{*}}^{*} B^{s^{*}}
$$

and $d$ is the order of difference. This research employs differencing with order one denoted as VAR-X $\left(p, 1, s^{*}\right)$ :

$$
\begin{aligned}
\phi_{p}(B)(1-B)^{d} Z_{t} & =\theta_{s^{*}}^{*}(B) X_{t}+a_{t}, \\
Z_{t}^{*} & =\sum_{i=1}^{p} \Phi_{i} Z_{t-1}^{*}+\sum_{i=0}^{s^{*}} \theta_{i}^{*} X_{t-1}+a_{t},
\end{aligned}
$$

where

$Z_{t}$ : is the $m \times 1$ series vector, is the $m \times m$ identity matrix, and $m$ is the number of series $\Phi_{p}:$ is a $m \times m$ matrix sized, while $m$ is a matrix sized $m \times m$.

\subsection{Selection of the Best Model}

The selection of the best models in this study is done by using Root Mean Square Error (RMSE) for in-sample forecasting and Mean Absolute Percentage Error (MAPE) for out-ofsample forecasting [11][14]

$$
\begin{aligned}
& \mathrm{RMSE}=\sqrt{\frac{\sum_{l=1}^{L}\left(Z_{n+l}-\hat{Z}_{n}(l)\right)^{2}}{L}} \text { and } \\
& \text { MAPE }=\frac{1}{L} \sum_{l}^{L}\left|\frac{Z_{n+l}-\hat{Z}_{n(l)}}{Z_{n+l}}\right| \times 100
\end{aligned}
$$

where $Z_{n+l}$ is out-of-sample data, $\hat{Z}_{n}(l)$ is forecast value and $L$ is the total out-of-sample data. 


\section{Methodology}

\subsection{Data Source and Research Variables}

This study uses daily data of the International Monetary Fund (IMF) and World Gold Council data from 1st June 2010 to 28th February 2018. The data contains the U.S. dollar exchange rate of South Africa Rand, Brazil Peso, and Australian dollar. The notations corresponding to the research variables are summarized in Table 1. The data is divided into training (in-sample), from 1st June 2010 to 28th February 2017, and testing (out-of-sample) sets, from 1st March 2017 to 28 th February 2018.

Table 1: Research Variable

\begin{tabular}{|c|c|c|}
\hline Time $(t)$ & Variable & Variable Name \\
\hline 1 & $X_{t}$ & GP for the price of 1 ounce of Gold in US dollar at time $t$ \\
\hline 2 & $Z_{1, t}$ & SAER for South Africa rand exchange rate at time $t$ \\
\hline 3 & $Z_{2, t}$ & BER for Brazil peso exchange rate at time $t$ \\
\hline 4 & $Z_{3, t}$ & AER for Australia dollar exchange rate at time $t$ \\
\hline
\end{tabular}

\subsection{Analysis Steps}

The proposed model building in the presence of exchange rate and gold price as an exogenous variable is described in this section.

The exchange rate and gold price data is also looked at by using the Transfer function as follows:

I. Preparing the input series for single input (Gold price) and output series Exchange rates.

II. Identify time series plots, ACF plots, and PACF. If it is not stationary invariance, then the transformation is done, while if not stationary in mean, then differencing is done.

III. Test the suitability of the model by fulfilling the white noise assumption.

IV. Do Prewhitening on the input series to obtain $a_{t}$.

V. Do Prewhitening on each output series to obtain $\beta_{t}$.

VI. Perform cross-correlation calculations (Cross-correlation) and autocorrelation for the series of inputs and outputs that have been prewhitening.

VII. Set the value $(b, r, s)$ that connects the input series and output to guess the model of the transfer function.

VIII. Estimate the initial noise series $n_{t}$ and calculate auto-correlation, partial autocorrelation and line spectrum for this series. 
IX. Assign $\left(p_{n}, q_{n}\right)$ to model ARIMA $\left(p_{n}, 0, q_{n}\right)$ from noise series $n_{t}$.

X. Estimate the transfer function model parameters. Estimate the parameters of the transfer function model using the method of Conditional Least Square.

XI. Perform a diagnostic test of the transfer function model by calculating the autocorrelation for the residual value of the model $(b, r, s)$ connecting the output series and the input series and then calculate cross-correlation between the residual value $\left(\hat{a}_{t}\right)$ with the residual $\left(a_{t}\right)$ that has been prewhitening.

XII. Forecast the values that will come with the transfer function model.

XIII. Calculate the RMSE and MAPE as in (5) and (6), respectively, of data testing for the Transfer function.

The steps that need to be done in the forecasting stage with the VARI-X method are:

I. Check the stationarity of the in-sample data using Box-Cox transformation and DickeyFuller test.

II. Identify the order of the VAR model based on the lowest value of AICc and MPCCF plot.

III. Modeled the exchange rate and exogenous price of gold in-sampled data using the VARI$\mathrm{X}$ method, and parameter significance checking at a maximum alpha of $10 \%$ and white noise assumption.

IV. Calculate the value of in-sample estimates and forecast out-sample or intervals using the resulting model at points (3).

V. Calculate the estimation of the in-sample covariance matrix and the matrix forecast outsample covariance based on point (4).

VI. Modeling VARI-X model based on the result of the lowest AICc and MPCCF plot followed by calculating the performance of the model using RMSE and MAPE.

VII. Forecast the values of the exchange rate and the exogenous price of gold.

\section{Results, Analysis and Evaluation}

\subsection{Characteristics of Exchange Rate across Countries with Gold Price}

In this descriptive analysis, patterns of exchange rates in the dollar (Australia), Peso (Brazil), Rand (South Africa), and gold price are shown using a time series plot. The time series plots of the exchange rate and gold price from 1st June 2010 to 28th February 2018 are shown in Figure 1. The plots indicate that for South Africa, the exchange rate increases at an initial stage and then start decreasing until it reaches a particular point again where it started to increase, but at a slower rate, the Brazilian exchange rate started falling an early stage and then continue fluctuating, the Australian exchange rate also started increasing slowly but decreased at a rapid rate while gold price initially started increasing until its get to a particular point when it started 
falling steadily as this shows that there are some outliers. In addition to using the time series plot to know the exchange rate characteristics in Australia, Brazil, South Africa, and gold price data, we also use descriptive statistics. The descriptive statistics of the exchange rate and gold price data are shown in Table 2.

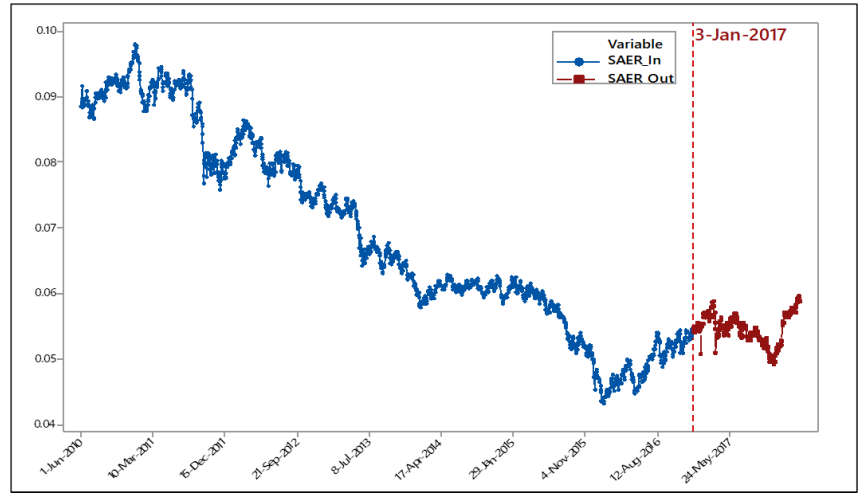

(a)

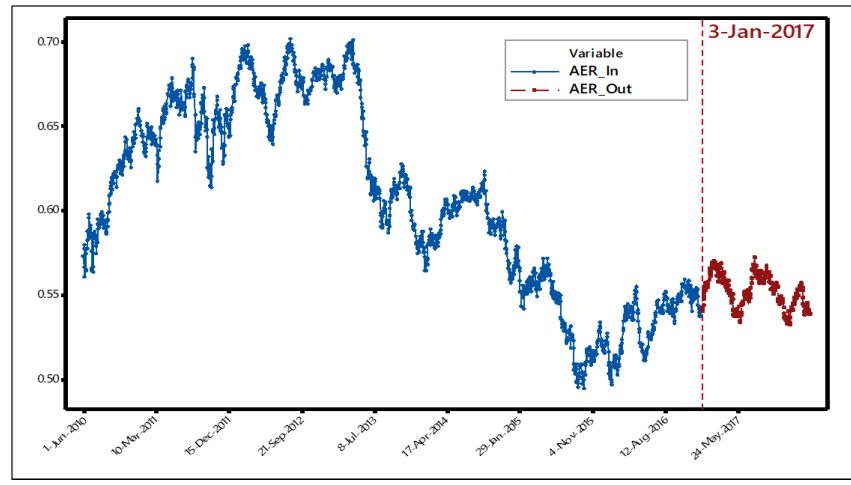

(c)

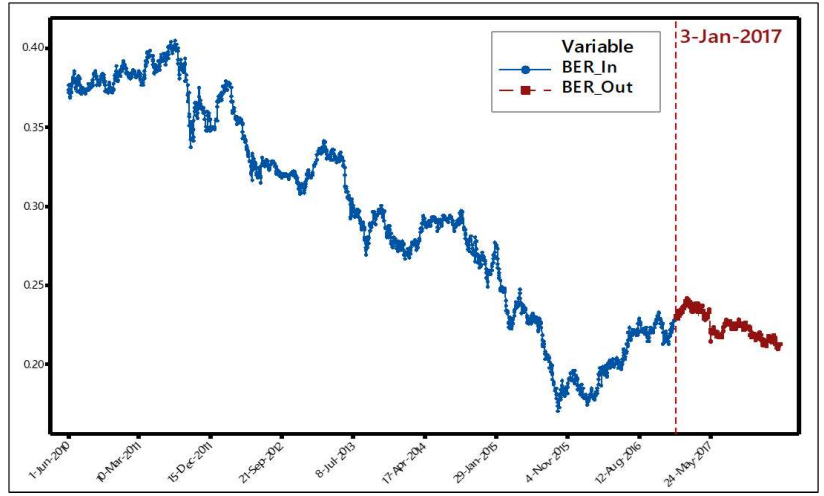

(b)

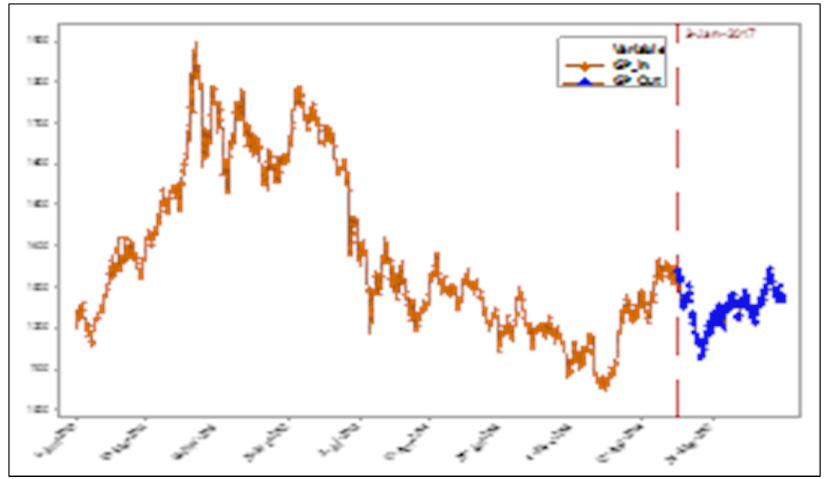

(d)

Figure 1: Time Series Plot of (a) Australian Exchange Rate, (b) Brazilian Exchange Rate, (c) South African Exchange Rate and (d) Gold Prize

From Table 2, we found out that the total observations in this study are 1936, mean of the gold price from 1st June 2010 to 28th February 2018 is 1341, the standard deviation of 193.9439, 0.0559 for the gold price and Australia, 0.0665 dollars for Brazil and 0.0431 dollars for South Africa. The highest exchange rate is for Australia with 0.7020, and the lowest exchange rate is 0.0980 for South Africa with Brazil 0.4052. The mean of the Australian Exchange rate is 0.5982 while that of Brazil is 0.2854 dollars.

\subsection{Modeling of the Exchange rate and Gold Price using ARIMA}

In modeling the exchange rate and gold price, the ARIMA model requires identifying the stationarity in mean and variance. The Box-Cox transformation and differencing are used in order to make the data stationary, after which the $p, d, q$ order is determined and then the ACF and PACF plotted. The residual assumption of the gold price is shown in Table 3. 
Table 2: Descriptive Statistics of Exchange Rate and Gold Price

\begin{tabular}{|l|c|c|c|c|c|}
\hline Variable & No. Obs & Mean & St. Dev & Min & Max \\
\hline Gold in US Dollar & 1936 & 1364 & 193.9439 & 1049 & 1895 \\
\hline Australia Dollar & 1936 & 0.5982 & 0.0559 & 0.4947 & 0.7020 \\
\hline Brazil Peso & 1936 & 0.2854 & 0.0665 & 0.1701 & 0.4052 \\
\hline South Africa Rand & 1936 & 0.067 & 0.0148 & 0.0431 & 0.0980 \\
\hline
\end{tabular}

Table 3: Residual Assumption Test for Gold Price

\begin{tabular}{|c|c|c|c|c|}
\hline ARIMA Model & Lags & $\chi^{2}$ & Df & P-value \\
\hline \multirow{3}{*}{$([21], 1,0)$} & 6 & 5.48 & 5 & 0.3604 \\
\cline { 2 - 5 } & 12 & 9.99 & 11 & 0.5310 \\
\cline { 2 - 5 } & 18 & 20.39 & 17 & 0.2548 \\
\cline { 2 - 5 } & 24 & 26.84 & 23 & 0.2828 \\
\hline \multirow{3}{*}{$(0,1,[21])$} & 6 & 5.44 & 5 & 0.3644 \\
\cline { 2 - 5 } & 12 & 10.04 & 11 & 0.5266 \\
\cline { 2 - 5 } & 18 & 20.49 & 17 & 0.2500 \\
\cline { 2 - 5 } & 24 & 26.94 & 23 & 0.2585 \\
\hline
\end{tabular}

Table 3 informs that the p-value from ARIMA $([21], 1,0)$ model and ARIMA $(0,1,[21])$ still have greater values than 0.05 , and none of the autocorrelation function of the residuals is insignificant as the white noise assumption has been met. Furthermore, we look at the residual assumption of exchange rate univariate in Table 4 . The residual test assumption includes the white noise test and normal distribution. It aims to know whether the residuals of the data are independent and normally distributed. Based on Table 4, all the models met the white noise assumption. This noise is indicated by a p-value greater than $\alpha=0.05$.

The next stage is to write the ARIMA model for each data as formulated in equation (7)(10). The equation of the exogenous gold price using subset ARIMA model of $(0,1,[21])$ could be written as

$$
X_{1, t}=X_{1, t-1}-0.0566 a_{t-21}+a_{t} .
$$

The models for the South African, Australian, and Brazilian exchange rates using subset ARIMA $([8,13,16], 1,0), \operatorname{ARIMA}(0,1,1)$, and subset ARIMA $(0,1,[7])$ respectively, are written in equation (8)-(10) as follows.

$$
\begin{aligned}
& Z_{1, t}=Z_{1, t-1}+0.0547 Z_{t-8}-0.0503 Z_{t-13}-0.0484 Z_{t-16}+a_{t} \\
& Z_{2, t}=Z_{2, t-1}+0.07483 a_{t-1}+a_{t} . \\
& Z_{3, t}=Z_{3, t-1}-0.06632 a_{t-7}+a_{t} .
\end{aligned}
$$


Table 4: Residual Assumption test for Exchange rate ARIMA

\begin{tabular}{|c|c|c|c|c|c|c|}
\hline Series & ARIMA Model & Lags & $\chi^{2}$ & Df & P-value & Normality Test \\
\hline \multirow{4}{*}{ SA. Rand } & \multirow{4}{*}{$([8,13,16], 1,0)$} & 6 & 7.40 & 5 & 0.0601 & \multirow{4}{*}{$\mathrm{D}=0.05, \mathrm{P}-$ Value $<0.01$} \\
\hline & & 12 & 14.92 & 11 & 0.0932 & \\
\hline & & 18 & 23.98 & 17 & 0.0654 & \\
\hline & & 24 & 31.98 & 23 & 0.0589 & \\
\hline \multirow{4}{*}{ Australia dollar } & \multirow{4}{*}{$(0,1,1)$} & 6 & 4.23 & 5 & 0.2379 & \multirow{4}{*}{$\mathrm{D}=0.04$, P-Value $<0.01$} \\
\hline & & 12 & 7.94 & 11 & 0.5406 & \\
\hline & & 18 & 9.46 & 17 & 0.8523 & \\
\hline & & 24 & 11.61 & 23 & 0.9495 & \\
\hline \multirow{4}{*}{ Brazil Peso } & \multirow{4}{*}{$(0,1,[7])$} & 6 & 4.81 & 5 & 0.1864 & \multirow{4}{*}{$\mathrm{D}=0.05$, P-Value $<0.01$} \\
\hline & & 12 & 10.36 & 11 & 0.3222 & \\
\hline & & 18 & 12.08 & 17 & 0.6729 & \\
\hline & & 24 & 15.03 & 23 & 0.8212 & \\
\hline
\end{tabular}

\subsection{Transfer Function Approach}

To forecast the exchange rate and exogenous gold price with the Transfer function approach first identifies the ARIMA model in the input series, which is the gold price. The data used is data in-sample. The approximate $(b, r, s)$ value for the Transfer function model is determined based on CCF plot results between $a_{t}$ and parameter $b$ if the delay period before the input series affects the output series as the first $x_{t}$ lag affect the significance of $y_{t}$. The determination of $\mathrm{s}$ is by estimating how long the series $y_{t}$ continues to be influenced by the series $x_{t}$, while the value of $r$ shows that the value of $y_{t}$ is influenced by its past value so that it will form a pattern.

Table 5-7 shows the model's parameter estimates for the model with no mean term; see the model in equation (11)-(13). It indicates the lag and the number of the impulse response at which the parameters appear. Its estimated values are given with their corresponding autoregressive parameters as they are also referred to as the lagged value of the South African Exchange rate with 12 shifts. The values provide a significance test for the parameter estimates and indicate whether some terms in the model might not be necessary. As it is clearly seen that the $p$-values are also statistically significant. The Transfer function equation model and the noise time series for the South African Exchange rate could be written as:

$$
Z_{1, t}=0.6424 x_{t-12}+\frac{1}{1-0.04893 B^{8}+0.04807 B^{10}+0.0653 B^{13}-0.05748 B^{19}} a_{t} .
$$

Table 6 indicates that the model has no mean term. It estimated values are given with one autoregressive parameter and coefficient of the input term. The $p$-values are seen to be significant and the noise time series and transfer function model for the Australian exchange 
rate could be written as

$$
Z_{2, t}=1.4501 x_{t-12}+\frac{1}{1+0.0686 B} a_{t}
$$

Table 5: Parameter Estimation for South African Exchange Rate

\begin{tabular}{|c|c|c|c|}
\hline Order $(b, r, s)$ & Parameter & Estimate & p-value \\
\hline \multirow{3}{*}{$(b=12, r=0, s=[8,10,13,19])$} & $\theta_{8}$ & 0.04893 & 0.0475 \\
\cline { 2 - 4 } & $\theta_{10}$ & -0.04807 & 0.0516 \\
\cline { 2 - 4 } & $\theta_{13}$ & -0.06538 & 0.008 \\
\cline { 2 - 4 } & $\theta_{19}$ & 0.05748 & 0.0204 \\
\cline { 2 - 4 } & $\omega_{0}$ & 0.64249 & 0.0006 \\
\hline
\end{tabular}

Table 6: Parameter Estimation for Australian Exchange Rate

\begin{tabular}{|c|c|c|c|}
\hline Order $(b, r, s)$ & Parameter & Estimate & p-value \\
\hline \multirow{2}{*}{$(b=12, r=0, s=0)$} & $\theta_{1}$ & -0.0686 & 0.0055 \\
\cline { 2 - 4 } & $\omega_{0}$ & 1.4501 & 0.0290 \\
\hline
\end{tabular}

Table 7: Parameter Estimation for Brazilian Exchange Rate

\begin{tabular}{|c|c|c|c|}
\hline Order $(b, r, s)$ & Parameter & Estimate & p-value \\
\hline \multirow{3}{*}{$(b=12, r=0, s=[2,5,8])$} & $\phi_{1}$ & 0.06716 & 0.0070 \\
\cline { 2 - 4 } & $\omega_{0}$ & 0.74915 & 0.0675 \\
\cline { 2 - 4 } & $\omega_{2}$ & 0.98323 & 0.0166 \\
\cline { 2 - 4 } & $\omega_{5}$ & 1.18950 & 0.0036 \\
\cline { 2 - 4 } & $\omega_{8}$ & -1.19711 & 0.0034 \\
\hline
\end{tabular}

Parameter estimates of the Brazilian exchange rate model as reported in Table 7 do not indicate any mean term as its estimated values are given with one autoregressive parameter and the input terms' coefficient. The $p$-values are seen to be significant with the order of parameters been $(b=12, r=0, s=[2,5,8])$. The noise term series and transfer function could be written as

$$
Z_{3, t}=0.74915 x_{t-12}-0.98323 x_{t-14}-1.18950 x_{t-17}-1.19711 x_{t-20}+\frac{1}{1-0.06716 B} a_{t} .
$$

The model predicts change in the Brazilian exchange rate, with some fraction of the previous change, plus a random error and some fraction of the random error in the earlier period. 


\subsubsection{Comparison of ARIMA and Transfer Function}

The ARIMA, which is a univariate model, is used as an input for the Transfer function. In econometrics, in particular, the ARIMA model is a generalization of an ARMA. The purpose of this feature is to make the model fit the data as well as possible. Thus, comparing these two models helps identify which one has a dominant effect on the exchange rate and gold price. The models are looked at using RMSE and MAPE criteria that have the smallest out-sample data, and the best model is employed to forecast for the next 12 periods. The RMSE and MAPE values comparison are presented of the two models in Table 8.

Table 8: Comparison of ARIMA and Transfer Function

\begin{tabular}{|l|c|c|c|c|}
\hline \multirow{2}{*}{ Series } & \multicolumn{2}{|c|}{ ARIMA } & \multicolumn{2}{c|}{ Transfer Function } \\
\cline { 2 - 5 } & RMSE & MAPE & RMSE & MAPE \\
\hline South Africa & $\mathbf{0 . 0 0 0 2 9}$ & $\mathbf{0 . 0 1 0 6}$ & 0.00030 & 0.0167 \\
\hline Australia & $\mathbf{0 . 0 1 0 3 7}$ & $\mathbf{0 . 0 1 5 8 6}$ & 0.01032 & 0.0159 \\
\hline Brazil & 0.00245 & 0.07713 & $\mathbf{0 . 0 0 2 3 4}$ & $\mathbf{0 . 0 7 3 8 5}$ \\
\hline
\end{tabular}

Based on comparison as reported in Table 8, the results show that the ARIMA model is the best model for forecasting the South African and Australian exchange rates due to a better MAPE of 0.0106 and 0.01586, whereas the Transfer function is the best model for forecasting the Brazilian Exchange rate as they are all indicated with a very low RMSE and MAPE. The best model for each data is as shown below. The best South Africa Exchange rate ARIMA model could be written as:

$$
Z_{1, t}=Z_{1, t-1}+0.0547 Z_{t-8}-0.0503 Z_{t-13}-0.0484 Z_{t-16}+a_{t}
$$

The best Australian exchange rate using the ARIMA model is:

$$
Z_{2, t}=Z_{2, t-1}+0.07483 a_{t-1}+a_{t}
$$

The Transfer function model for the Brazilian exchange rate could be written as

$$
Z_{3, t}=0.74915 x_{t-12}-0.98323 x_{t-14}-1.19711 x_{t-17}-1.19711 x_{t-20}+\frac{1}{1-0.6716 B} a_{t} .
$$

\subsection{Modeling of the Exchange Rate and Gold Price using VARIX}

In VARIX modeling, we only use in-sample data for each exchange rate and gold price data. In modeling the exchange rate and gold price across countries, the data must be stationary in both variances and mean. Stationary identification can be shown using a time series plot of the exchange rate and gold price in Figure 2.

From Figure 2, it can be inferred that the Exchange rate and the gold price are stationary in variances and mean after been differenced. Since the stationary time series through differencing is an important part fitting the VARIX model. Also, it makes it very easy to predict as its statistical properties will be the same in the future as they have been in the past. The further 


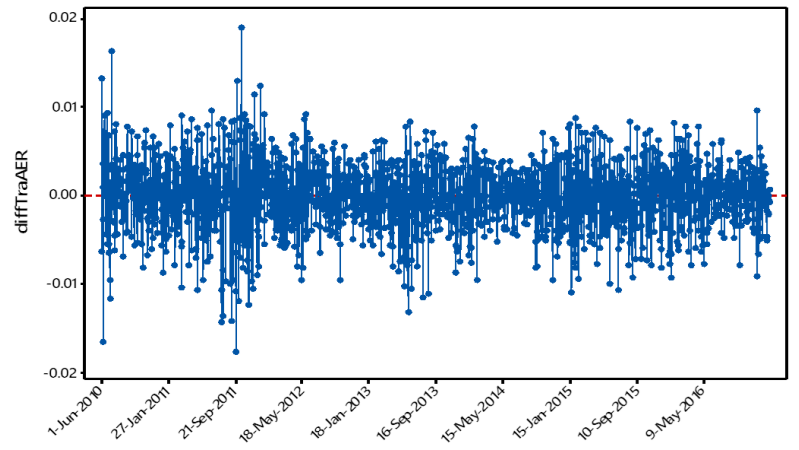

(a)

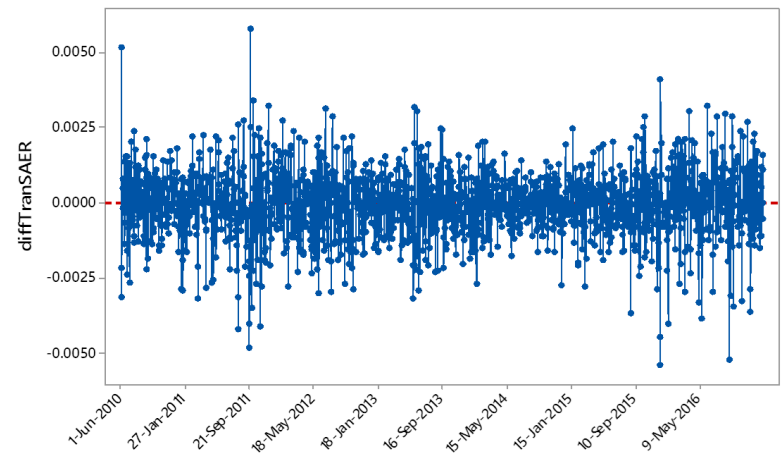

(c)

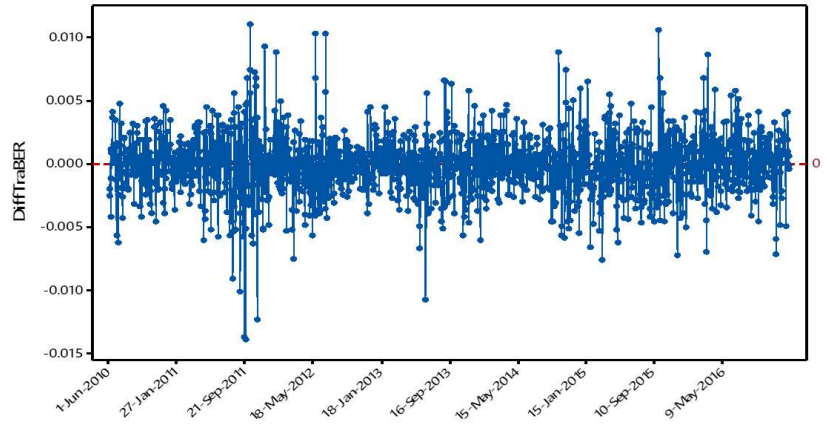

(b)

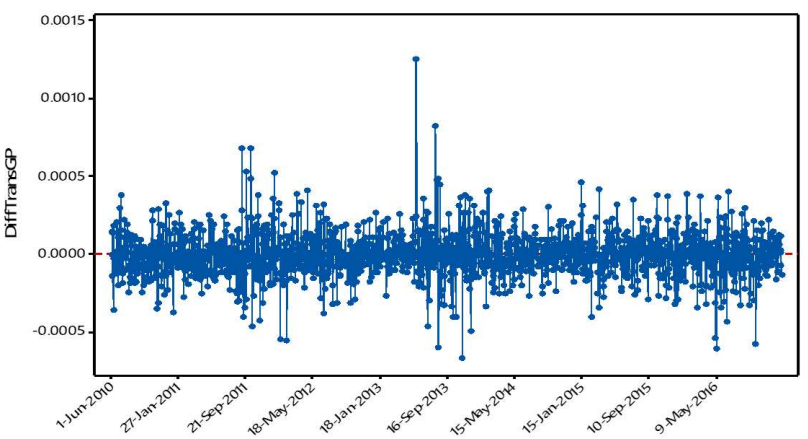

(d)

Figure 2: Stationary Time Series Plot of (a) Australian Exchange Rate, (b) Brazilian Exchange Rate, (c) South African Exchange Rate and (d) Gold Price

\begin{tabular}{|c|c|c|c|c|c|c|c|c|c|c|c|c|c|c|c|c|c|c|c|c|c|c|c|c|c|}
\hline \multicolumn{26}{|c|}{ Schematic Representation of Cross Correlations } \\
\hline Variable/Lag & 0 & 1 & 2 & 3 & 4 & 5 & 6 & 7 & 8 & 9 & 10 & 11 & 12 & 13 & 14 & 15 & 16 & 17 & 18 & 19 & 20 & 21 & 22 & 23 & 24 \\
\hline SAER & ++ &.+ &.++ & $\cdots$ &..- & $\because$ & $\cdots$ & $\cdots$ &..+ & $\cdots$ & $\because-$ & $\cdots$ & $\cdots$ &..- & $\cdots$ & $\cdots$ & $\cdots$ & $\cdots$ & $\cdots$ &..+ & $\cdots$ & $\cdots$ & $\cdots$ & $\cdots$ & ... \\
\hline BER & +4 & $\ldots$ & $\cdots$ & $\ldots$ & $\ldots$ &..+ & $\ldots$ & + & $\cdots$ & $\ldots$ & $\cdots$ & $\ldots$ & $\ldots$ & $\cdots$ & $\cdots$ & ... & $\ldots$ & $\cdots$ &..+ & $\ldots$ & ... & $\cdots$ & $\cdots$ & $\cdots$ & ... \\
\hline AER & ++ &.+ & $+\ldots$ & $\cdots$ & $\cdots$ & $\cdots$ & $\cdots$ &.+ & $\cdots$ & $\cdots$ & $\cdots$ & $\ldots$ & $\cdots$ & -+ & $\cdots$ &..- & $\cdots$ & $\ldots$ & $\ldots$ & $\cdots$ & $\cdots$ & $\ldots$ & $\ldots$ & $\cdots$ & ... \\
\hline \multicolumn{26}{|c|}{+ is $>2{ }^{*}$ std error, - is $<-2^{*}$ std error, . is between } \\
\hline
\end{tabular}

Figure 3: Schematic Representation of Cross Correlation

identification process can be done by looking at the minimum AICc values to choose the VARIX model's order, as shown in Table 9.

Based on the AICc values presented in Table 9, the exchange rate indicates that the AR order's smallest AICc value (-37.08432) is at lag four. To further progress, we look at the schematic representation of cross-correlation that shows CCF as in Figure 3. It shows that the point of having a value is between two times the standard error. The positive sign is less than the limit of 0.2 , which means a positive correlation. The number of positive signs that occur simultaneously in the Matrix Correlation Function is significant at lag 0. 
Table 9: AICC of Tentative Exchange Rate of VARIX Model

\begin{tabular}{|c|c|c|c|}
\hline Lag & AICc & Lag & AICc \\
\hline Lag 0 & -36.82068 & Lag 7 & -37.07467 \\
\hline Lag 1 & -37.04876 & Lag 8 & -37.07537 \\
\hline Lag 2 & -37.07657 & Lag 9 & -37.06712 \\
\hline Lag 3 & -37.07511 & Lag 10 & -37.06421 \\
\hline Lag 4 & -37.08432 & Lag 11 & -37.05773 \\
\hline Lag 5 & -37.08393 & Lag 12 & -37.04900 \\
\hline Lag 6 & -37.07605 & & \\
\hline
\end{tabular}

Granger causality Wald Test is used to see whether there is any relationship between the variables. As shown in Table 10, it can be concluded that in the exchange rate between countries, all of them are statistically significant and has a strong relationship with each other and can also influence gold price, but the gold price does not have a strong influence over them. It can be seen that gold price is the exogenous variable and fit $\operatorname{VARX}(4,1,20)$ model; it also shows that we cannot reject Granger Causality from the exchange rate variables for the price using a 0.05 significance level.

Table 10: Granger-Causality Wald Test

\begin{tabular}{|c|c|c|c|c|c|}
\hline Test & Group1 Variable & Group2 Variables & DF & Chi-Square & Pr $>$ Chisq \\
\hline & & South Africa & & & \\
\hline 1 & Gold Price & Brazil & 12 & 9.07 & 0.6967 \\
\hline & & Australia & & & \\
\hline 2 & Brazil & Australia & 8 & 325.91 & $<0.0001$ \\
\hline & & South Africa & & & \\
\hline 3 & South Africa & Brazil & 8 & 20.97 & 0.0072 \\
\hline & & Australia & & & \\
\hline 4 & Australia & South Africa & 8 & 113.29 & $<0.0001$ \\
\hline & & Brazil & & & \\
\hline
\end{tabular}

Following the minimum information criteria detection and Matrix Cross-Correlation Function $(\mathrm{MCCF})$, the exchange rate level can be obtained from the $\operatorname{VARX}(4,1,20)$ model. The exchange rate models across countries are shown in equation (14)-(16). 
The South African Rand Model could be written as:

$$
\begin{aligned}
Z_{1, t}^{*} & =-0.4283 X_{t}^{*}-0.6457 X_{t-12}^{*}+0.0208 Z_{2, t-1}^{*}-0.0208 Z_{2, t-2}^{*}-0.0188 Z_{2, t-3}^{*} \\
& +0.0188 Z_{3, t-2}^{*}-0.07261 Z_{2, t-3}^{*}+0.0166 Z_{3, t-3}^{*}-0.0473 Z_{2, t-4}^{*}+0.0188 Z_{2, t-5}^{*}+a_{t} .
\end{aligned}
$$

The mathematical model for the Brazilian Peso exchange rate is

$$
\begin{aligned}
Z_{2, t}^{*}= & 0.6667 X_{t-12}^{*}-0.992 X_{t-14}^{*}-1.1191 X_{t-17}^{*}+0.9512 X_{t-20}^{*}-0.7553 Z_{1, t-2}^{*} \\
& -0.0887 Z_{2, t-2}^{*}+0.0675 Z_{3, t-1}^{*}+0.1538 Z_{1, t-2}^{*}+0.0967 Z_{1, t-3}^{*} \\
& -0.0967 Z_{1, t-4}^{*}-0.0449 Z_{2, t-4}^{*}+a_{t} .
\end{aligned}
$$

The model for the Australian dollar exchange rate is

$$
\begin{aligned}
Z_{3, t}^{*}= & 1.1590 X_{t-12}^{*}+0.7720 Z_{1, t-1}^{*}-0.1428 Z_{3, t-1}^{*}+0.3729 Z_{1, t-2}^{*}-0.0536 Z_{3, t-2} \\
& +0.0536 Z_{3, t-3}-0.1795 Z_{1, t-4}^{*}+0.1795 Z_{1, t-5}^{*}+a_{t} .
\end{aligned}
$$

Based on the restricted models, it is clearly seen that the exchange rate influences gold price, and each country is independent of its own. A falling U.S dollar tends to increase the gold price because other currencies and commodities worldwide increase in value when the dollar falls. Conversely, a strong U.S dollar tends to reduce gold price since gold and dollar have an inverse relationship.

\subsubsection{Comparison of the Transfer Function and VARIX Models}

The model that has been obtained is the Transfer function model and VARIX. Their value has been looked at using RMSE and MAPE criteria. Models with the smallest RMSE and MAPE values out-sample data would be the best model to predict the next periods. The following RMSE and MAPE values comparison is presented of all models in Table 11.

Table 11: Comparison of the Transfer function and VARI-X

\begin{tabular}{|l|c|c|c|c|}
\hline \multirow{2}{*}{ Series } & \multicolumn{2}{|c|}{ Transfer Function } & \multicolumn{2}{c|}{ VARIX } \\
\cline { 2 - 5 } & RMSE & MAPE & RMSE & MAPE \\
\hline South Africa & $\mathbf{0 . 0 0 0 2 9}$ & $\mathbf{0 . 0 1 6 7 7}$ & 0.00034 & 0.01603 \\
\hline Australia & 0.01032 & 0.01591 & $\mathbf{0 . 0 1 0 2 9}$ & $\mathbf{0 . 0 1 5 5 5}$ \\
\hline Brazil & $\mathbf{0 . 0 0 2 3 3}$ & $\mathbf{0 . 7 3 8 5 2}$ & 0.00290 & 1.02690 \\
\hline
\end{tabular}

From the comparison in Table 11, the result shows that VARIX is the best model for forecasting the Australian exchange rate, whereas the Transfer function is the best model for forecasting South African and Brazilian exchange rates. The lowest exchange rate is forecasted for South Africa followed by Brazil and then Australia with the least. 


\section{Conclusion and Future Work}

Based on the analysis and discussion that has been done, the following conclusions can be drawn that the characteristics of the exchange rate in South Africa, Brazil,and Australia have a similar pattern from the 1st June 2010 to 27th February 2018 as it shows a fluctuation in the dollar. ARIMA model is used for forecasting gold price data univariately as input for Transfer Function and VARIX models. ARIMA model has a parsimonious representation of the stochastic process. It also shows its flexibility in incorporating explanatory variables, making it one of the best amongst Transfer Function and VARIX. Based on the Transfer function modeling, we found the in-sample and out-sample forecast for exchange rate with gold price as an input variable that the Transfer function model has met the requirement and that it is the best model for forecasting South African and Brazilian exchange rate when the RMSE and MAPE criteria are used.

The best VARIX model produced at each level based on the minimum information criteria is at lag four and VARIX $(4,1,20)$ model. We also found out that it is the best model for forecasting the Australian exchange rate, which has the smallest RMSE of 0.01029 and 0.01555 MAPE. It clearly shows that it does not only predict exchange rate across three countries, but also can see the interaction between countries exchange rate with gold price as an exogenous variable. Hence, these findings will help policy makers and stakeholders formulate effective policies for controlling the exchange rate and gold prices.

Recommendations can be given for further research in which other models can be used to forecast the exchange rate and gold prices, such as Neural Network, GARCH, ARCH, VARMA, VAR, etc. Also, monthly prices can be forecasted using ARIMA, transfer function, and VARIX. Few factors that are related to the exchange rate and gold prices were used in this research. This study can be expanded by considering other countries with a high tendency to influence the gold price.

\section{Acknowledgement}

The authors would like to thank the research sponsors, especially the Department of Statistics, Faculty of Science and Data Analytics, ITS Surabaya, the Director of Directorate of International Partnership through KNB scholarship. In addition, we would also like to thank the referees for their valuable suggestions and comments that led to an improved manuscript.

\section{References}

[1] Toraman, C., Basarir, C. and Bayramoglu, M. F. Determination of factors affecting the price of gold: a study of MGARCH model. Business and Economics Research Journal. 2011. 2(4): 37-50.

[2] Mombeini, H. and Yazdani-Chamzini, A. Modeling gold price via artificial neural network. Journal of Economics, Business and Management. 2015. 3(7): 699-703.

[3] Pitigalaarachchi, P. A. A. C., Jayasundara, D. D. M. and Chandrasekara, N. V. Modeling and forecasting Sri Lankan gold prices. International Journal of Sciences: Basic and Applied Research. 2016. 27(3): 247-260. 
[4] Ghosh, D., Levin, E. J., Macmillan, P. and Wright, R.E. Gold as an inflation hedge? Studies in Economics and Finance. 2004. 22(1): 1-25.

[5] Evans, M. D. D. and Lyons, R. K. Order flow and exchange rate dynamics. Journal of Political Economy. 2002. 110(1): 170-180.

[6] Wei, S. J. and Kim, J. The Big Players in the Foreign Exchange Market: Do They Trade on Information or Noise? NBER Working Paper No. 6256. National Bureau of Economic Research. 1997.

[7] Cai, J., Cheung, Y. L., Lee, R. S. K. and Melvin, M. "Once-in-a-generation" yen volatility in 1998: fundamentals, intervention and order flow. Journal of International Money and Finance. 2001 20(3): 327-347.

[8] Jordaan, A.C. Determining South Africa's export potential to Australia: a panel data approach. South African Journal of Economic and Management Sciences. 2015. 18(3): 354-365.

[9] Suhartono and Lee, M. H. A Hybrid Approach based on Winters model and weighted fuzzy time series for Forecasting trend and seasonal data. Journal of Mathematics and Statistics. 2011. 7(3): 177-183.

[10] Cryer, J. D. and Chan, K. S. Time Series Analysis: With Applications in R. 2nd Edition. New York: Springer-Verlag. 2008.

[11] Wei, W. W. S. Time Series Analysis: Univariate and Multivariate Methods. 2nd Edition. New York: Pearson Addison Wesley. 2006.

[12] Faraway, J. and Chris, C. Time series forecasting with neural networks: a comparative study using the air line data. Journal of the Royal Statistical Society: Series C (Applied Statistics). 1998. 47(2): 231-250.

[13] Apriliadara, M., Suhartono and Prastyo, D. D. VARI-X model for currency inflow and out flow forecasting with Eid Fitr effectin Indonesia. AIP Conference Proceedings. 2016. 1746: 020041.

[14] Gooijer, J. G. D, and Hyndman, R. J. 25 years of time series forecasting. International Journal of Forecasting. 2006. 22(3): 443-473. 